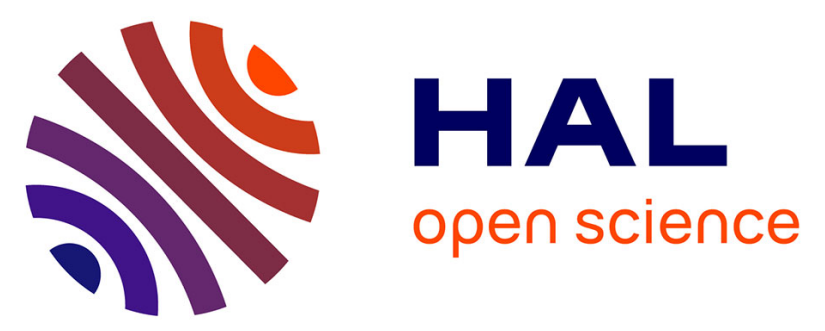

\title{
Chlordecone potentiates hepatic fibrosis in chronic liver injury induced by carbon tetrachloride in mice
}

Elise Tabet, Valentine Genet, François Tiaho, Catherine Lucas-Clerc, Moana Gelu-Simeon, Claire Piquet-Pellorce, Michel Samson

\section{- To cite this version:}

Elise Tabet, Valentine Genet, François Tiaho, Catherine Lucas-Clerc, Moana Gelu-Simeon, et al.. Chlordecone potentiates hepatic fibrosis in chronic liver injury induced by carbon tetrachloride in mice. Toxicology Letters, 2016, 255, pp.1-10. 10.1016/j.toxlet.2016.02.005 . hal-01274228

HAL Id: hal-01274228

https://hal-univ-rennes1.archives-ouvertes.fr/hal-01274228

Submitted on 3 Jun 2016

HAL is a multi-disciplinary open access archive for the deposit and dissemination of scientific research documents, whether they are published or not. The documents may come from teaching and research institutions in France or abroad, or from public or private research centers.
L'archive ouverte pluridisciplinaire HAL, est destinée au dépôt et à la diffusion de documents scientifiques de niveau recherche, publiés ou non, émanant des établissements d'enseignement et de recherche français ou étrangers, des laboratoires publics ou privés. 
Chlordecone potentiates hepatic fibrosis in chronic liver injury induced by carbon tetrachloride in mice

Running title: Chlordecone potentiates hepatic fibrosis

Elise Tabet ${ }^{1,2,3}$, Valentine Genet ${ }^{1,2,3}$, François Tiaho ${ }^{1,2,3}$, Catherine Lucas-Clerc ${ }^{2,4}$, Moana Gelu-Simeon ${ }^{1,5}$, Claire Piquet-Pellorce ${ }^{1,2,3}$, Michel Samson ${ }^{1,2,3^{*}}$

${ }^{1}$ Institut National de la Santé et de la Recherche Médicale (Inserm), U.1085, Institut de Recherche Santé Environnement and Travail (IRSET), F-35043 Rennes, France.

${ }^{2}$ Université de Rennes 1, F-35043 Rennes, France.

${ }^{3}$ Structure Fédérative BioSit UMS 3480 CNRS-US18 Inserm, F-35043 Rennes, France. ${ }^{4}$ Service de Biochimie CHU Rennes, Université de Rennes 1; F-35043 Rennes, France.

${ }^{5}$ Service d'Hépato-Gastroentérologie CHU Pointe à Pitre; F-97159 Pointe à Pitre Cedex, France.

*Correspondence author at: INSERM-U1085, IRSET, Université de Rennes 1, 2, Avenue du Professeur Léon Bernard, 35043 RENNES Cedex, France. Tel.: (+33) 22323 5927; Fax (+33) 223234794. 


\section{Highlights}

- Hepatic impact of chronic co-exposure to chlordecone and CCl4 investigated in mouse model.

- Chlordecone enhances the liver damage in CCl4 murine chronic hepatitis.

- Chlordecone enhances the progression of liver fibrosis in mice. 


\begin{abstract}
Chronic liver damage due to viral or chemical agents leads to a repair process resulting in hepatic fibrosis. Fibrosis may lead to cirrhosis, which may progress to liver cancer or a loss of liver function, with an associated risk of liver failure and death. Chlordecone is a chlorinated pesticide used in the 1990s. It is not itself hepatotoxic, but its metabolism in the liver triggers hepatomegaly and potentiates hepatotoxic agents. Chlordecone is now banned, but it persists in soil and water, resulting in an ongoing public health problem in the Caribbean area. We assessed the probable impact of chlordecone on the progression of liver fibrosis in the population of contaminated areas, by developing a mouse model of chronic co-exposure to chlordecone and a hepatotoxic agent, carbon tetrachloride $\left(\mathrm{CCl}_{4}\right)$. After repeated administrations of chlordecone and $\mathrm{CCl}_{4}$ by gavage over a 12-week period, we checked for liver damage in the exposed mice, by determining serum liver transaminase (AST, ALT) levels, histological examinations of the liver and measuring the expression of genes encoding extracellular matrix components. The co-exposure of mice to $\mathrm{CCl}_{4}$ and chlordecone resulted in significant increases in ALT and AST levels. Chlordecone also increased expression of the Col1A2, MMP-2, TIMP-1 and PAI-1 genes in $\mathrm{CCl}_{4}$-treated mice. Finally, we demonstrated, by quantifying areas of collagen deposition and alpha-SMA gene expression, that chlordecone potentiated the hepatic fibrosis induced by $\mathrm{CCl}_{4}$. In conclusion, our data suggest that chlordecone potentiates hepatic fibrosis in mice with $\mathrm{CCl}_{4}$-induced chronic liver injury.
\end{abstract}

\title{
Abbreviations
}

AST: Aspartate aminotransferase

ALT: Alanine aminotransferase

CD: Chlordecone

$\mathrm{CCl}_{4}$ : Carbon tetrachloride

$\alpha$-SMA: $\alpha$-smooth muscle actin

ECM: Extracellular matrix

Keywords: Liver; Fibrosis; Chlordecone; CCl4; Collagen; Kepone 


\section{Introduction}

Fibrogenesis is a wound-healing response to repeated liver injury. It is triggered in response to chronic liver damage, regardless of the cause of the damage: viral infections, alcohol abuse, drug exposure, metabolic dysfunctions or autoimmune disorders. It manifests as a progressive replacement of the liver parenchyma with scar tissue. This process takes place over many years and can lead to other complications, such as cirrhosis, leading to liver failure or an increase in the risk of hepatocellular carcinoma. Hepatic fibrosis is characterized by the excessive accumulation of extracellular matrix (ECM) (Friedman, 2003). At advanced stages of the disease, there may be six times more ECM in fibrotic livers than in normal livers (Benyon and Iredale, 2000). This accumulation results from an imbalance between the synthesis and degradation of ECM components (Arthur, 2000), such as fibrillar collagen, essentially collagen type I (Tsukada et al., 2006), matrix metalloproteinases (MMPs) (Takahara et al., 1995) and their tissue inhibitors (TIMPs) (Benyon and Iredale, 2000).

Humans are exposed, on a daily basis, to various toxic agents, chemicals and drugs in the environment. The liver is the major site of detoxification for these compounds in the body. This organ may therefore be considered a target of their toxicity. In humans, hepatotoxicity due to exposure to alcohol, drugs such as acetaminophen, imidazole fungicidal agents and other chemicals has also been studied in a context of exposure to mixtures of these agents. It has been shown that exposure to alcohol + acetaminophen, or alcohol + imidazole fungicidal agent mixtures results in worse damage to the human liver than exposure to any of these agents alone (Zimmerman and Maddrey, 1995).

Many animal models for studying the molecular processes underlying the pathophysiology of the liver during exposure to hepatotoxic compounds administered alone or in combination have been developed, to improve our understanding of the molecular mechanisms of action of these hepatotoxic compounds and the host response, and to identify biological markers of liver damage. As in humans, mixtures of chemical agents were found to aggravate liver damage in most of the animal models studied (Brautbar and Williams, 2002).

In animals, diverse causes of fibrogenesis have been studied, but the principal in vivo model of fibrosis is based on the repeated administration of carbon tetrachloride $\left(\mathrm{CCl}_{4}\right)$ over a period of several weeks (Brautbar and Williams, 2002; Chang et al., 2005). $\mathrm{CCl}_{4}$ is a hepatotoxic agent that can induce liver fibrosis, and even cirrhosis, after long-term exposure. $\mathrm{CCl}_{4}$ is known to trigger centrilobular hepatic necrosis and the first event in its hepatotoxicity 
is its metabolic activation in the liver (Weber et al., 2003). $\mathrm{CCl}_{4}$ is increased by other agents, such as alcohol, in situations of co-exposure in animals (Benyon et al., 1996; Chobert et al., 2012; McLean and McLean, 1966). In particular, the hepatotoxicity of this compound has been shown to be increased in models of co-exposure to pesticides, such as mirex and chlordecone.

Chlordecone, also known as kepone, is an organochlorine pesticide that was produced essentially from 1958 through 1975 in the United States, for export to Latin America, Africa and Europe for use as an ant and cockroach poison. Kepone was also used to control banana root borer, primarily in the Caribbean area. Kepone production was banned in 1976 after it was discovered that the Life Science Products Company factory in Hopewell, Virginia, which was responsible for producing this chemical, had caused serious contamination of the environment and many of its workers were found to have medical problems. All workers at this factory presented symptoms of chlordecone poisoning, including headaches, anxiety, irritability and memory disturbance, abnormal hepatic function and defective spermatogenesis. Studies of chlordecone toxicity in humans and animal models implicated this agent in a broad array of syndromes, affecting the nervous and reproductive systems in particular. Chlordecone is known to accumulate mostly in the liver (Egle et al., 1978) triggering hepatomegaly (Guzelian, 1985). Chlordecone is not itself hepatotoxic, but several studies have shown that it can strongly potentiate the hepatotoxic effects of $\mathrm{CCl}_{4}$ in models of acute co-exposure (Curtis et al., 1979; Klingensmith et al., 1983; Mehendale, 1989).

Chlordecone is no longer used, but it persists in the soils and water of the Caribbean area. It thus remains a public health problem, due to its potential contribution to many chronic diseases, including liver diseases.

In this study, we developed a mouse model of chronic co-exposure to chlordecone and $\mathrm{CCl}_{4}$, to assess the impact of chlordecone on the development and progression of liver fibrosis. We evaluated the liver damage caused by the interaction between chlordecone and $\mathrm{CCl}_{4}$, the expression of genes involved in matrix remodeling and the amount of collagen deposited in mouse livers.

\section{Materials and Methods}

\section{Animals and experimental protocol}


Eight-week-old male C57Bl/6 mice were purchased from Janvier (Le Genest-sur-Isle, France) and reared in specific pathogen-free (SPF) conditions in the local animal house, in accordance with French laws and institutional guidelines for the handling and care of experimental animals (accreditation of M. Samson \#3596).

Animals were assigned to four groups at random. In the first group, the mice received olive oil daily, by gavage, as a control treatment. In the second group, mice were treated, once weekly, with $\mathrm{CCl}_{4}$ (Sigma-Aldrich, St. Louis, MO, USA) at a dose of $0.1 \mathrm{~g} / \mathrm{kg}$. In the third group, the mice received chlordecone (Santa Cruz Biotechnology) daily, at a dose of 5 $\mathrm{mg} / \mathrm{kg}$. In the fourth group, the mice received chlordecone at a dose of $5 \mathrm{mg} / \mathrm{kg}$ daily for two weeks and then $0.1 \mathrm{~g} / \mathrm{kg} \mathrm{CCl}$ once weekly, in addition to their daily dose of chlordecone. $\mathrm{CCl}_{4}$ and chlordecone were diluted in olive oil and administered by oral gavage. During the 12 weeks of the study, the mice were observed and their body weight was measured once weekly. The doses of the chemicals used were well tolerated and no deaths occurred. Blood was collected from the mice $48 \mathrm{~h}$ and $72 \mathrm{~h}$ after the administration of $\mathrm{CCl}_{4}$ in weeks $5,7,9$ and 12 of the study. The mice were killed $72 \mathrm{~h}$ after the administration of the last dose of $\mathrm{CCl}_{4}$. The liver was removed and fragments of this organ were fixed in $4 \%$ paraformaldehyde and embedded in paraffin or frozen in liquid nitrogen in the presence of the cryoprotectant isopentane. Serum aspartate aminotransferase (AST) and alanine aminotransferase (ALT) levels were determined according to IFCC primary reference procedures, with an Olympus AU2700 Autoanalyser® (Olympus Optical Optical Co. Ltd., Tokyo, Japan).

\section{RNA isolation and RT-qPCR}

We homogenized liver tissue samples weighing approximated $100 \mathrm{mg}$ and extracted total RNA in Trizol reagent (Invitrogen). The first-strand cDNA was produced with SuperScriptTM II Reverse Transcriptase (Invitrogen). The cDNA was then amplified, with the GAPDH housekeeping gene as a control. Quantitative PCR was performed with the fluorescent dye SYBR Green and the double strand-specific SYBR® Green system (Applied Biosystems), with an ABI 7900 HT Prism sequence analyzer (Applied Biosystems). Total cDNA (30 ng) was used as a template for amplification, with the specific primer pair (Table 1) used at a final concentration of $300 \mathrm{nM}$. Each measurement was performed in triplicate. We determined 18S mRNA levels as a control, and the level of expression of each gene studied is expressed relative to that of the $18 \mathrm{~S}$ gene. The primers used were, for collagen $1 \mathrm{~A} 2$ (forward: 
5'ATGCACATCAATGTGGAGGA3'),

for

MMP-2

(forward:

5'TTGAGAAGGATGGCAAGTAT3', reverse: 5'ATGGTAAACAAGGCTTCATG3'), for TIMP-1 (forward: 5'TTCCAGTAAGGCCTGTAGC3', reverse: 5'TTATGACCAGGTCCGAGTT3'), for PAI-1 (forward: 5'TCCAGAAGCAGAGAGGGAAA3', reverse: 5'CAGTGCAGCTCTGACTCACC3'), for 18S (forward: 5'CGCCGCTAGAGGTGAAATTC3', reverse: 5'ATGCACATCAATGTGGAGGA3').

\section{Immunocytochemistry and histology}

For the assessment of liver injury, $4 \mu \mathrm{m}$-thick sections of paraffin-embedded liver were cut, placed on microscope slides and stained with hematoxylin and eosin (H\&E). Slides were scanned with a Nanozoomer NDP and images were acquired with NDP viewer software.

Collagen deposition in treated mouse livers was assessed by Sirius red staining on $4 \mu \mathrm{m}$-thick paraffin-embedded liver sections. The stained area was measured, over the total liver surface, with NIS element software. The percentage of the total liver area displaying fibrosis was calculated.

Liver sections (10 $\mu$ m thick) from frozen samples, were fixed on slides, by incubation in 4\% formaldehyde for 10 minutes. They were then washed and immunostained for $\alpha$-smooth muscle actin (Cy3-conjugated monoclonal anti-actin $\alpha$-smooth muscle antibody, Clone 1A4, Sigma) for 1 hour. The liver sections were then washed in 1x PBS, mounted in fluorescence mounting medium (Dako) and scanned with the Nanozoomer NDP for image acquisition. Four mice per set of treatment conditions were analysed and the $\alpha-$ SMA stained was quantified with Image J software, using a common threshold for all samples.

\section{Multiphoton SHG microscopy}

Multiphoton SHG images were acquired on a photonic imaging platform (PIXEL facility of GIS EUROPIA, University of Rennes 1, France, http://pixel.univ-rennes1.fr). The imaging setup consisted of a confocal Leica TCS SP2 scanning head (Leica Microsystems, Mannheim, Germany) mounted on a Leica DMIRE2 inverted microscope and equipped with a MAITAI Spectra Physics femtosecond laser (Spectra Physics, Santa Clara, CA, USA). A Leica dry objective HCPLAPO 10X $(\mathrm{NA}=0.4)$ and Leica condenser S23 $(\mathrm{NA}=0.53)$ were used to apply a constant $12 \mathrm{~mW}$ of excitation at $820 \mathrm{~nm}$ to the sample, and for collection, respectively. BG39 bandpass and $410 \mathrm{~nm}$ IR (10 nm FWHM) filters were placed before the 
trans-detection photomultiplier tube (PMT) detector. Constant gains were achieved by setting $650 \mathrm{~V}$ and $750 \mathrm{~V}$ at PMTs for the trans-detection of the forward SHG signal and the epidetection of the autofluorescence signal, respectively. Images were acquired with $20 \mu \mathrm{m}$ thick deparaffinized liver slices. Four random fields of view per liver section were imaged. The SHG signal was analyzed and quantified with open-source ImageJ software. Briefly, background pixels were set to NaN (not-a-number) values and a common threshold was set for all samples. The SHG signal was quantified by determining the percentage of pixels with a signal above the threshold.

\section{Statistical analysis}

Kruskal-Wallis one-way analysis of variance (ANOVA) was performed, and mean differences between experimental groups were assessed in nonparametric Mann-Whitney Utest, with GraphPad Prism5 software. For all statistical analyses, * denotes $p<0.05$, ** denotes $p<0.01$ and $* * *$ denotes $p<0.001$.

\section{Results}

\section{Chlordecone administration potentiates the chronic liver injury induced by $\mathbf{C C l}_{4}$}

We investigated the impact of chlordecone on chronic liver injury, by treating mice with $\mathrm{CCl}_{4}$ and chlordecone by gavage, according to the experimental design presented in figure $1 \mathrm{~S}$. Measurements of body weight over a period of 12 weeks revealed no significant difference between the four treatments (Fig. 2S), liver-to-body weight ratio was significantly higher in mice treated with chlordecone alone or in combination with $\mathrm{CCl}_{4}$ than in mice treated with $\mathrm{CCl}_{4}$ alone or oil (negative control) (Fig.1A). Levels of the transaminases ALT and AST were measured in the collected serum after 5, 7, 9 and 12 weeks of treatment (Fig. 1B and 3S). Chlordecone gavage had no effect on ALT and AST levels, whereas treatment with $\mathrm{CCl}_{4}$ alone caused a significant increase of the levels of these enzymes in the serum. The exposure of mice to both $\mathrm{CCl}_{4}$ and chlordecone resulted in significantly higher levels of ALT and AST than exposure to $\mathrm{CCl} 4$ alone or oil, indicating that hepatic injury was more severe in conditions of co-exposure. The staining of liver sections with hematoxylin and eosin showed the necrotic areas to be larger after combined treatment with $\mathrm{CCl}_{4}$ and chlordecone than after exposure to $\mathrm{CCl}_{4}$ exposure alone, whereas liver sections from mice treated with chlordecone alone or with oil contained no zones of hepatic necrosis (Fig. 1C). Moreover, the areas of 
necrosis increased over time for all treatments. These measurements demonstrate that chlordecone administration potentiates the chronic liver injury caused by $\mathrm{CCl}_{4}$.

\section{Chlordecone enhances expression of the Col1A2, MMP-2, TIMP-1 and PAI-1 genes in the $\mathrm{CCl}_{4}$-treated mouse model}

Chronic liver injury is usually associated with changes in the extracellular matrix. Molecular changes in the livers of mice treated with oil, chlordecone, $\mathrm{CCl}_{4}$ or with both chlordecone and $\mathrm{CCl}_{4}$ were investigated by studying the expression of a number of genes encoding components of the extracellular matrix. Expression of the gene encoding type 1 collagen, the most abundant collagen in fibrotic tissues, increased significantly over time in mice exposed to both chlordecone and $\mathrm{CCl}_{4}$ and the level of expression of this gene was higher in these mice than in $\mathrm{CCl}_{4}$-treated mice (Fig. 2A). Expression of the genes encoding matrix metalloproteinase-2 and its inhibitor (TIMP-1) was upregulated in the livers of mice treated with both chlordecone and $\mathrm{CCl}_{4}$ (Fig. 2B, 2C). Expression of the gene encoding PAI-1, which is known to enhance collagen deposition in injured livers, was slightly stronger in mice exposed to both chlordecone and $\mathrm{CCl}_{4}$ than in mice exposed to $\mathrm{CCl}_{4}$ alone (Fig. 2D). These changes in gene expression suggest that there is an imbalance in the synthesis and degradation of extracellular matrix components in mice treated with both chlordecone and $\mathrm{CCl}_{4}$ and that this imbalance results in greater liver injury.

\section{Chlordecone potentiates the hepatic fibrosis induced by $\mathrm{CCl}_{4}$}

As repeated liver injury leads to liver fibrosis, we assessed the impact of chlordecone on chronic CCl4-induced liver fibrosis development and progression, by assessing collagen deposition in mouse liver. Sirius red staining was performed on mouse liver sections, for all treatments. Control and chlordecone-treated mice had normal collagen distributions, whereas CCl4-treated mice presented excessive collagen deposition, increasing with treatment duration. Collagen deposition levels were highest in liver sections from mice exposed to both chlordecone and $\mathrm{CCl}_{4}$ (Fig. 3A). Quantification of the areas of collagen deposition on sections stained with Sirius red showed that a significantly larger area of the liver was covered with collagen in mice treated with both chlordecone and $\mathrm{CCl}_{4}$ than in mice treated with $\mathrm{CCl}_{4}$ alone (Fig. 3B).

We also assessed collagen deposition by second harmonic generation (SHG), to provide further evidence for a role of chlordecone in potentiating $\mathrm{CCl}_{4}$-induced hepatic fibrosis. 
Representative liver sections were imaged by multiphoton microscopy, and we found that the SHG signal was stronger on imaged liver samples obtained from mice treated with both chlordecone and $\mathrm{CCl}_{4}$ for 12 weeks than in mice treated with $\mathrm{CCl}_{4}$ alone (Fig. 4A). The quantification of SHG signal images showed that significantly more collagen was deposited in mice exposed to both $\mathrm{CCl}_{4}$ and chlordecone than in mice treated with $\mathrm{CCl}_{4}$ alone (Fig. $4 \mathrm{~B}$ ). The imaging results obtained for Sirius red staining and SHG analysis clearly demonstrate that treatment with both chlordecone and $\mathrm{CCl}_{4}$ increases the size of the fibrotic area in mouse liver.

\section{Chlordecone upregulates the expression of $\alpha$-SMA in $\mathrm{CCl}_{4}$-treated mice}

The excessive production of extracellular matrix during the development and the progression of liver fibrosis is mostly due to hepatic stellate cells (HSCs). These cells undergo a process of activation in chronically damaged livers, characterized by the gain of a myofibroblastic phenotype and by the production of $\alpha$-smooth muscle actin ( $\alpha$-SMA) (Geerts, 2001). We assessed the impact of chlordecone on the production of $\alpha$-SMA protein in the livers of mice treated with oil, chlordecone, $\mathrm{CCl}_{4}$, or chlordecone $+\mathrm{CCl}_{4}$ for 5 or 12 weeks. Immunostaining for $\alpha$-SMA on liver sections yielded a positive signal when mice were treated with $\mathrm{CCl}_{4}$ for five weeks and a stronger signal when they were treated for 12 weeks. However, the exposure of mice to both chlordecone and $\mathrm{CCl}_{4}$ clearly enhanced the $\alpha$-SMA signal on liver sections (Fig. 5A). The quantification of $\alpha$-SMA staining revealed that the area displaying such staining was significantly larger in the livers of mice treated with both chlordecone and $\mathrm{CCl}_{4}$ than in those of mice exposed to $\mathrm{CCl}_{4}$ only (Fig. 5B)

\section{Discussion}

Chlordecone is a persistent environmental contaminant that its resistance to biodegradation and its high potential for bioaccumulation have hindered its elimination since the prohibition of its use. Thus, even though this toxic pesticide is no longer used, studies on the impact of chlordecone on human health will remain relevant for a long time to come. Hepatomegaly is the most frequent symptom observed in people exposed to chlordecone (Cohn et al., 1978). Indeed, as chlordecone accumulates in the liver and is eliminated slowly, the liver is a major target organ for studies of the toxicity of chlordecone (Belfiore et al., 2007; Egle et al., 1978). Studies in rodent models have shown that chlordecone can induce several molecular changes 
in the liver, including the induction of cytochrome P450 enzymes (Mehendale et al., 1977, 1978) and changes to cholesterol homeostasis (Carpenter and Curtis, 1991; Gilroy et al., 1994).

In this study, we investigated the impact of chlordecone on the development and progression of chronic liver diseases, such as hepatic fibrosis. We developed a mouse model of chronic exposure to chlordecone and to the hepatotoxic chemical $\mathrm{CCl}_{4}$. The interactions between chlordecone and several other chemicals have been studied in mouse and rat models, in acute exposure protocols involving the administration of only one or a few doses of chlordecone. For instance, chlordecone has been shown to potentiate the hepatotoxic and lethal effects of acetaminophen and bromotrichloromethane (Agarwal and Mehendale, 1982; Fouse and Hodgson, 1987). The impact of chlordecone on $\mathrm{CCl}_{4}$ hepatotoxicity has also been studied in models of acute co-exposure. Rodents subjected to chlordecone treatment and then challenged with $\mathrm{CCl}_{4}$ display enhanced bioactivation of $\mathrm{CCl}_{4}$ and a lack of hepatocyte regeneration (Klingensmith et al., 1983; Lockard et al., 1983).

In our model of chronic co-exposure, mice were treated by gavage for 10 days with a dose of $5 \mathrm{mg} / \mathrm{kg}$ chlordecone, to ensure that the animals received the whole dose and was saturated with chlordecone (Lagarrigue et al., 2014). After this pretreatment, the mice were challenged by gavage with a moderate dose of $\mathrm{CCl}_{4}(0.1 \mathrm{~g} / \mathrm{kg})$ once per week for $5,7,9$ and 12 weeks in addition to their daily dose of chlordecone $(5 \mathrm{mg} / \mathrm{kg})$. As previously reported, treatment with chlordecone induced hepatomegaly. Co-exposure to chlordecone and $\mathrm{CCl}_{4}$ significantly increased this hepatomegaly, in a time-dependent manner. Determinations of serum hepatic enzymes (AST and ALT), which are considered to be the principal indicators of liver injury (Pratt and Kaplan, 2000), showed the levels of these enzymes to be significantly higher in mice exposed to both chlordecone and $\mathrm{CCl}_{4}$, with the levels of these enzymes increasing with the duration of treatment. Further evidence for the impact of co-exposure to chlordecone and $\mathrm{CCl}_{4}$ on liver injuries was provided by the histological examination of livers, which showed larger areas of necrosis for mice exposed to both chemicals and for longer durations of treatment. We used the $\mathrm{CCl}_{4}$-induced chronic liver injury model to assess hepatic fibrosis. With the experimental strategy used, we were able to detect molecular changes due to the process of fibrogenesis and to observe typical liver fibrosis after $\mathrm{CCl}_{4}$ application between weeks 5 and 12 of the experiment. During fibrosis progression, changes in the composition of the ECM were observed, with an increase in fibrillar collagen production (Tsukada et al., 2006). We found that expression of the collagen type I gene was stronger in mice exposed to 
both chlordecone and $\mathrm{CCl}_{4}$ than in those exposed to $\mathrm{CCl}_{4}$ alone. Similarly, co-exposure to chlordecone and $\mathrm{CCl}_{4}$ led to an upregulation of MMP-2 and its inhibitor, TIMP-1 (Herbst et al., 1997), contributing to ECM remodeling. Our study thus reveals that pretreatment with chlordecone aggravates the molecular changes underlying fibrogenesis in the mouse model of $\mathrm{CCl}_{4}$-induced liver fibrosis.

From the fifth week of chronic treatment with $\mathrm{CCl}_{4}$ alone, we observed an increase in collagen deposition in mouse livers. Furthermore, treatment with both chlordecone and $\mathrm{CCl}_{4}$ resulted in significantly higher levels of collagen deposition, as shown by both Sirius red staining and multiphoton SHG analysis. Immunostaining for $\alpha$-SMA and its quantification in mouse liver showed that chlordecone clearly upregulated the production of this protein during fibrogenesis.

In conclusion, this study demonstrates that hepatic fibrosis can be influenced by chronic coexposure to chlordecone, which aggravates liver disease. In our mouse model, chlordecone potentiated hepatic fibrosis in animals with chronic liver injury induced by carbon tetrachloride. As chlordecone has been shown to potentiate the effects of hepatotoxic drugs, such as acetaminophen (Fouse and Hodgson, 1987), studies should be carried out on human populations living in chlordecone-contaminated areas, to check the effects of exposure to this chemical on chronic liver diseases.

\section{Conflict of interest}

The authors have no financial or commercial conflict of interest to declare.

\section{ACKNOWLEDGMENTS}

This work was supported by Inserm, Université de Rennes 1 and the ANR (Agence nationale de la recherche). For immunohistochemistry and animal house facilities, we would like to thank the dedicated platforms (i.e. H2P2 (Pascale Bellaud and Roselyne Viel), Arche (Laurence Bernard)) of SFR BIOSIT, University of Rennes 1, France. 


\section{REFERENCES}

Agarwal, A.K., Mehendale, H.M., 1982. Potentiation of bromotrichloromethane hepatotoxicity and lethality by chlordecone preexposure in the rat. Fundam Appl Toxicol 2, 161-167.

Arthur, M.J., 2000. Fibrogenesis II. Metalloproteinases and their inhibitors in liver fibrosis. Am J Physiol Gastrointest Liver Physiol 279, G245-249.

Belfiore, C.J., Yang, R.S., Chubb, L.S., Lohitnavy, M., Lohitnavy, O.S., Andersen, M.E., 2007. Hepatic sequestration of chlordecone and hexafluoroacetone evaluated by pharmacokinetic modeling. Toxicology 234, 59-72.

Benyon, R.C., Iredale, J.P., 2000. Is liver fibrosis reversible? Gut 46, 443-446.

Benyon, R.C., Iredale, J.P., Goddard, S., Winwood, P.J., Arthur, M.J., 1996. Expression of tissue inhibitor of metalloproteinases 1 and 2 is increased in fibrotic human liver. Gastroenterology 110, 821-831.

Brautbar, N., Williams, J., 2nd, 2002. Industrial solvents and liver toxicity: risk assessment, risk factors and mechanisms. Int J Hyg Environ Health 205, 479-491.

Carpenter, H.M., Curtis, L.R., 1991. Low dose chlordecone pretreatment altered cholesterol disposition without induction of cytochrome P-450. Drug Metab Dispos 19, 673-678.

Chang, M.L., Yeh, C.T., Chang, P.Y., Chen, J.C., 2005. Comparison of murine cirrhosis models induced by hepatotoxin administration and common bile duct ligation. World J Gastroenterol 11, 4167-4172. Chobert, M.N., Couchie, D., Fourcot, A., Zafrani, E.S., Laperche, Y., Mavier, P., Brouillet, A., 2012. Liver precursor cells increase hepatic fibrosis induced by chronic carbon tetrachloride intoxication in rats. Lab Invest 92, 135-150.

Cohn, W.J., Boylan, J.J., Blanke, R.V., Fariss, M.W., Howell, J.R., Guzelian, P.S., 1978. Treatment of chlordecone (Kepone) toxicity with cholestyramine. Results of a controlled clinical trial. N Engl J Med $298,243-248$.

Curtis, L.R., Williams, W.L., Mehendale, H.M., 1979. Potentiation of the hepatotoxicity of carbon tetrachloride following preexposure to chlordecone (kepone) in the male rat. Toxicol Appl Pharmacol 51, 283-293.

Egle, J.L., Fernandez, J.B., Guzelian, P.S., Borzelleca, J.F., 1978. Distribution and excretion of chlordecone (Kepone) in the rat. Drug Metab Dispos 6, 91-95. 
Fouse, B.L., Hodgson, E., 1987. Effect of chlordecone and mirex on the acute hepatotoxicity of acetaminophen in mice. Gen Pharmacol 18, 623-630.

Friedman, S.L., 2003. Liver fibrosis -- from bench to bedside. J Hepatol 38 Suppl 1, S38-53.

Geerts, A., 2001. History, heterogeneity, developmental biology, and functions of quiescent hepatic stellate cells. Semin Liver Dis 21, 311-335.

Gilroy, D.J., Carpenter, H.M., Curtis, L.R., 1994. Chlordecone pretreatment alters [14C]chlordecone and [14C]cholesterol transport kinetics in the perfused rat liver. Fundam Appl Toxicol 22, 286-292.

Guzelian, P.S., 1985. Clinical evaluation of liver structure and function in humans exposed to halogenated hydrocarbons. Environ Health Perspect 60, 159-164.

Herbst, H., Wege, T., Milani, S., Pellegrini, G., Orzechowski, H.D., Bechstein, W.O., Neuhaus, P., Gressner, A.M., Schuppan, D., 1997. Tissue inhibitor of metalloproteinase-1 and -2 RNA expression in rat and human liver fibrosis. Am J Pathol 150, 1647-1659.

Klingensmith, J.S., Lockard, V., Mehendale, H.M., 1983. Acute hepatotoxicity and lethality of CCl4 in chlordecone-pretreated rats. Exp Mol Pathol 39, 1-10.

Lagarrigue, M., Lavigne, R., Tabet, E., Genet, V., Thome, J.P., Rondel, K., Guevel, B., Multigner, L., Samson, M., Pineau, C., 2014. Localization and in situ absolute quantification of chlordecone in the mouse liver by MALDI imaging. Anal Chem 86, 5775-5783.

Lockard, V.G., Mehendale, H.M., O'Neal, R.M., 1983. Chlordecone-induced potentiation of carbon tetrachloride hepatotoxicity: a morphometric and biochemical study. Exp Mol Pathol 39, 246-255.

McLean, A.E., McLean, E.K., 1966. The effect of diet and 1,1,1-trichloro-2,2-bis-(p-

chlorophenyl)ethane (DDT) on microsomal hydroxylating enzymes and on sensitivity of rats to carbon tetrachloride poisoning. Biochem J 100, 564-571.

Mehendale, H.M., 1989. Mechanism of the lethal interaction of chlordecone and $\mathrm{CCl} 4$ at non-toxic doses. Toxicol Lett 49, 215-241.

Mehendale, H.M., Takanaka, A., Desaiah, D., Ho, I.K., 1977. Kepone induction of hepatic mixed function oxidases in the male rat. Life Sci 20, 991-997.

Mehendale, H.M., Takanaka, A., Desaiah, D., Ho, I.K., 1978. Effect of preexposure to kepone on hepatic mixed-function oxidases in the female rat. Toxicol Appl Pharmacol 44, 171-180.

Pratt, D.S., Kaplan, M.M., 2000. Evaluation of abnormal liver-enzyme results in asymptomatic patients. N Engl J Med 342, 1266-1271. 
Takahara, T., Furui, K., Funaki, J., Nakayama, Y., Itoh, H., Miyabayashi, C., Sato, H., Seiki, M., Ooshima, A., Watanabe, A., 1995. Increased expression of matrix metalloproteinase-II in experimental liver fibrosis in rats. Hepatology 21, 787-795.

Tsukada, S., Parsons, C.J., Rippe, R.A., 2006. Mechanisms of liver fibrosis. Clin Chim Acta 364, 33-60.

Weber, L.W., Boll, M., Stampfl, A., 2003. Hepatotoxicity and mechanism of action of haloalkanes: carbon tetrachloride as a toxicological model. Crit Rev Toxicol 33, 105-136.

Zimmerman, H.J., Maddrey, W.C., 1995. Acetaminophen (paracetamol) hepatotoxicity with regular intake of alcohol: analysis of instances of therapeutic misadventure. Hepatology 22, 767-773. 


\section{Figure Captions}

Figure 1: Chronic liver injury caused by $\mathrm{CCl}_{4}$ and chlordecone in $\mathrm{C57BL} / 6$ mice. Mice received oral gavage with olive oil, chlordecone ( $5 \mathrm{mg} / \mathrm{kg}$ body weight), $\mathrm{CCl}_{4}(0.1 \mathrm{~g} / \mathrm{kg}$ body weight) or chlordecone+ $\mathrm{CCl}_{4}$. They were killed at 5, 7, 9 and 12 weeks of the study. A) Liver-to-body weight ratio, demonstrating the occurrence of hepatomegaly in the treated mice. (B) Serum levels of ALT (IU/L) in mice at the four time points studied. (C) Liver sections stained with hematoxylin and eosin, showing the necrotic area in mice at 5 and 12 weeks of study. Scale bars $=500 \mu \mathrm{m}$. The different treatment groups are shown in (A) and $(\mathrm{B})$ as $\rightarrow$ for oil, $\cdots$ for chlordecone, $\rightarrow$ for $\mathrm{CCl}_{4}$ and $\cdots-$ for chlordecone $+\mathrm{CCl}_{4}$. The data shown are means \pm SD for four animals per group and the $p$-values for Mann-Whitney tests, at the right margin of the graphs, indicate the significance of differences between groups $(* * P<0.01 ; * * * P<0.001)$.

A

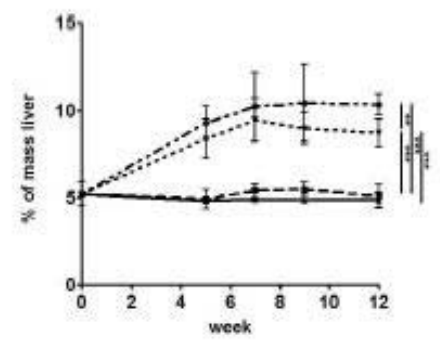

B
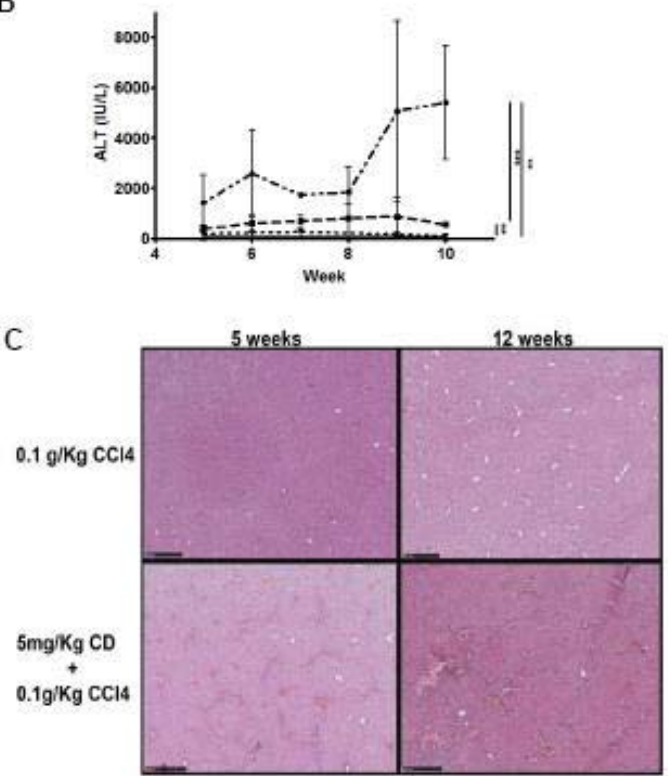
Figure 2: Reverse transcription-PCR analysis of collagen 1a2 mRNA levels. (A) MMP-2 (B), TIMP-1 (C) and PAI-1 (D). Liver total RNA was extracted from mice treated with oil, chlordecone, $\mathrm{CCl}_{4}$ or chlordecone+CCl4 for 5, 7, 9, or 12 weeks, as described in the materials and methods section. After RT-PCR analysis, mRNA levels were expressed as ratios relative to $18 \mathrm{~S}$ levels. The histogram bars corresponding to the different treatment groups are shown as $\square$ for oil, $\square$ for chlordecone, $\mathbb{Z}$ for $\mathrm{CCl}_{4}$ and $\mathbf{I I}$ for chlordecone $+\mathrm{CCl}_{4}$. The data shown are the means \pm SD for four animals in each group and the $p$-values for MannWhitney tests and one-way ANOVA test indicate the significance of differences between groups $(* P<0.05 ; * * P<0.01 ; * * * P<0.001)$.

A

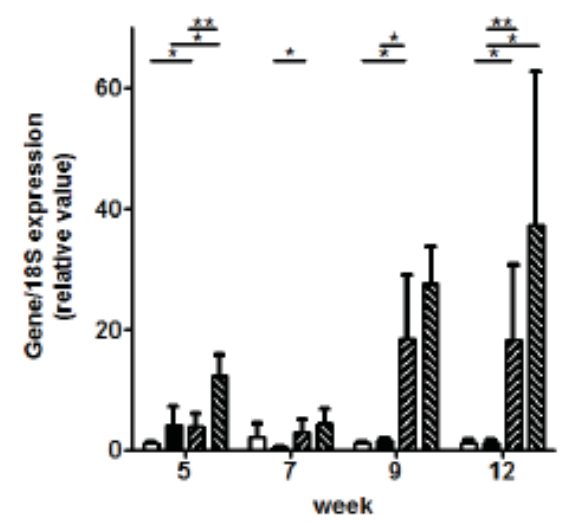

C

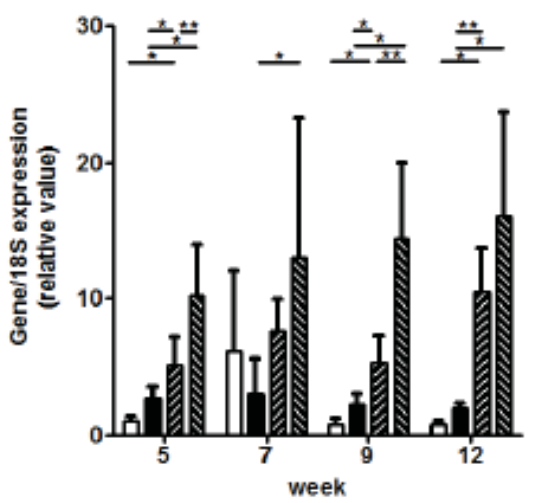

B

MMP-2

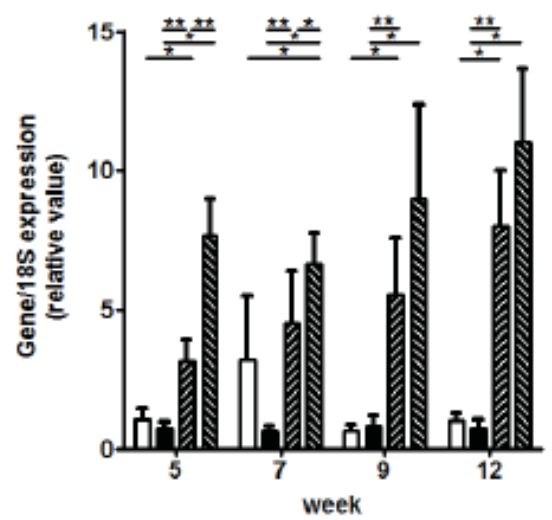

D

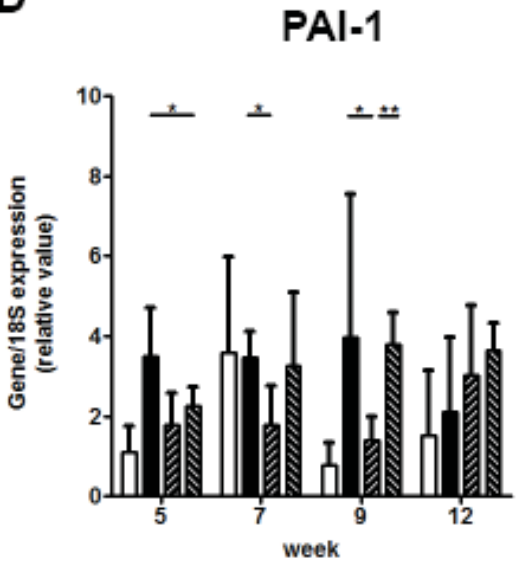


Figure 3: Effect of chlordecone on $\mathbf{C C l}_{4}$-induced liver fibrosis. Photomicrographs of liver sections stained with Sirius red from mice treated with oil, chlordecone $(5 \mathrm{mg} / \mathrm{kg}$ body weight), $\mathrm{CCl}_{4}\left(0.1 \mathrm{~g} / \mathrm{kg}\right.$ body weight) or chlordecone $+\mathrm{CCl}_{4}$ for $5,7,9$ and 12 weeks (Scale bars $=500 \mu \mathrm{m})(\mathbf{A})$. Sirius red staining for collagen was quantified with NIS element software and the percentage of the total liver area examined displaying fibrosis was calculated. The data shown are the means \pm SD for four animals in each group and $p$-values for Mann-Whitney tests, at the right margin of the graphs, indicate the significance of differences between groups $(* P<0.05)$.

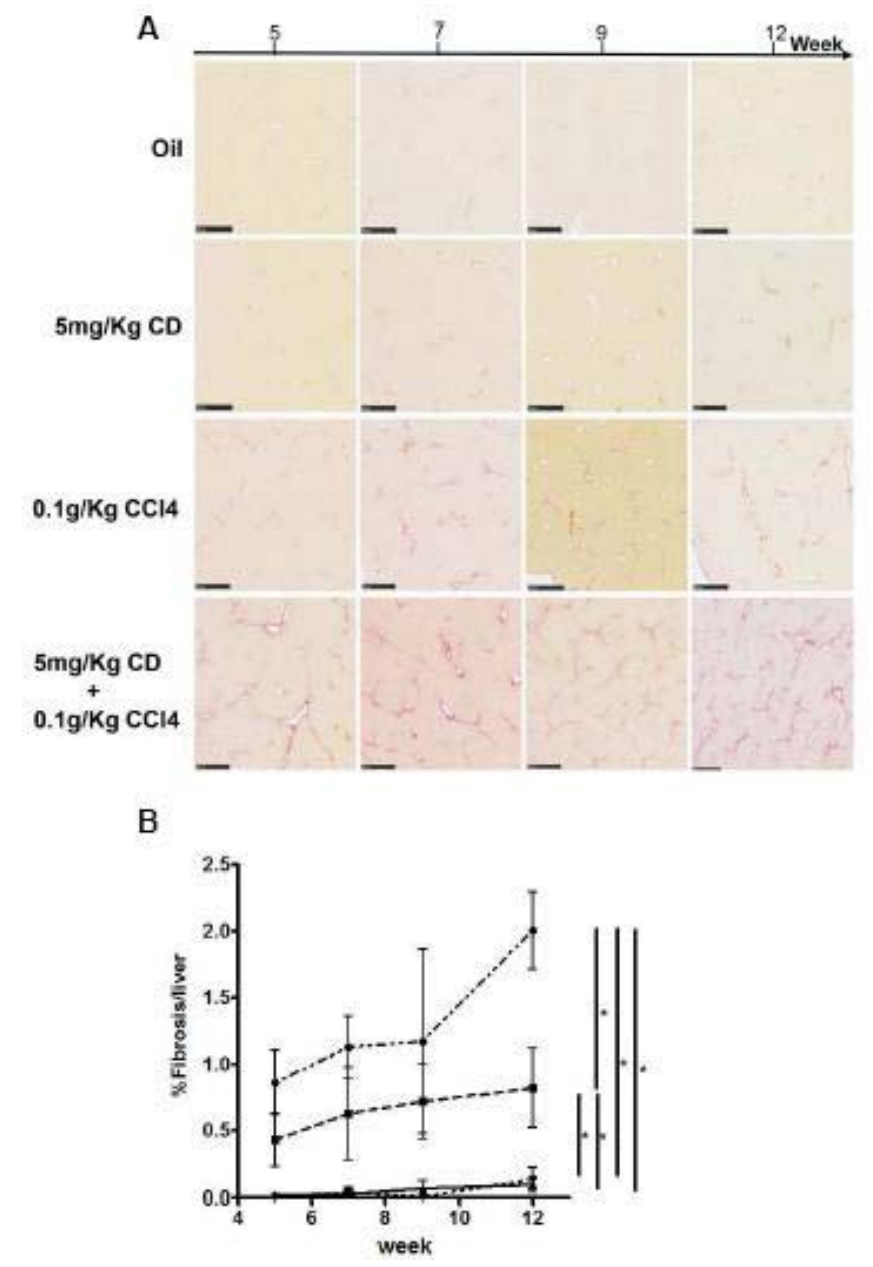


Figure 4: Imaging of liver fibrosis by second harmonic generation microscopy. (A) SHG images illustrating collagen deposition in the livers of mice treated with $\mathrm{CCl}_{4}$ only or chlordecone $+\mathrm{CCl}_{4}$ for 12 weeks. Scale bars $=500 \mu \mathrm{m}$. (B) The SHG signal was quantified with Image $\mathbf{J}$ software, as indicated in the methods section, and the percentage of the liver area displaying fibrosis was calculated for each mouse. The data shown are the means $\pm \mathrm{SD}$ for four animals per group and the $p$-values for Mann-Whitney tests indicate the significance of differences between groups $(* P<0.05)$.
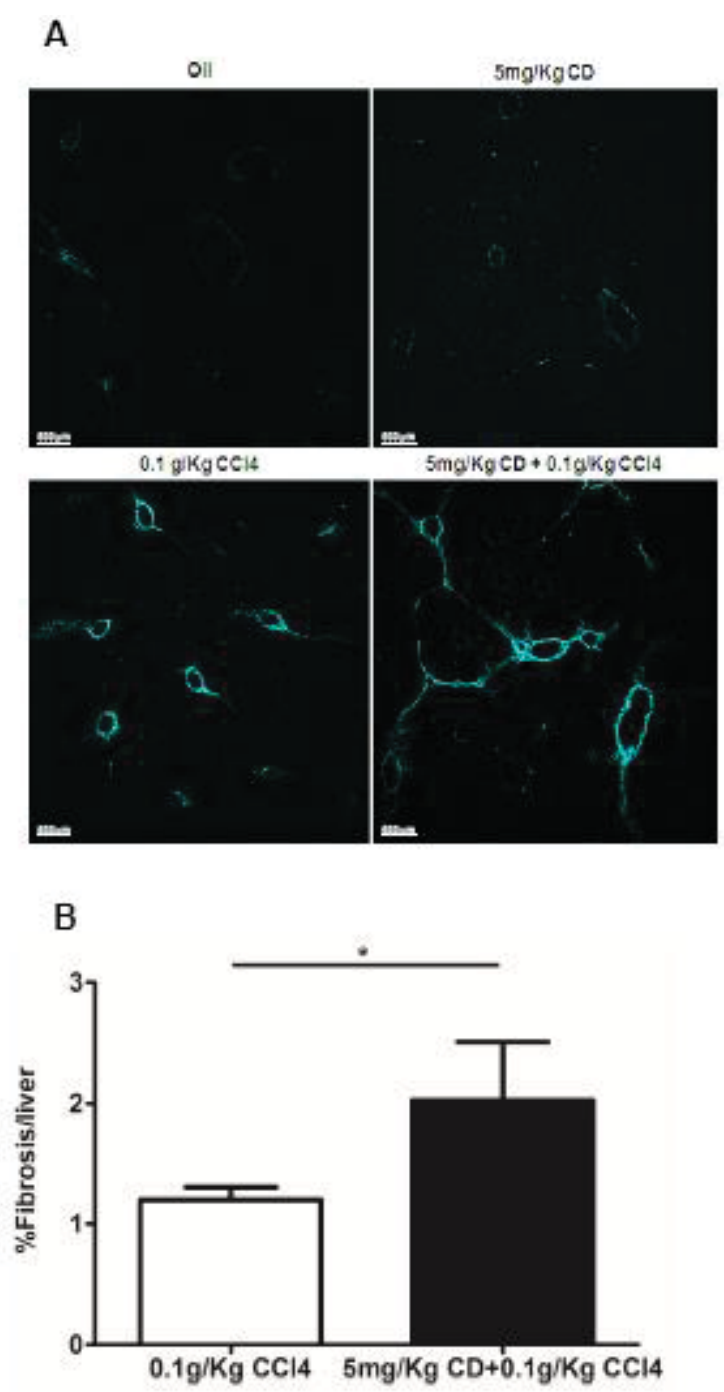
Figure 5: Immunostaining of liver sections for $\boldsymbol{\alpha}$-SMA. (A) Immunofluorescence images showing $\alpha$-SMA staining in the livers of mice treated with oil, chlordecone, $\mathrm{CCl}_{4}$ or chlordecone $+\mathrm{CCl}_{4}$ for 5 and 12 weeks. Scale bars $=500 \mu \mathrm{m}$. (B) Stained areas were quantified with Image $\mathrm{J}$ software and the data shown are means $\pm \mathrm{SD}$ for four animals in each group and the $p$-values for Mann-Whitney tests indicate the significance of differences between groups $(* P<0.05)$.

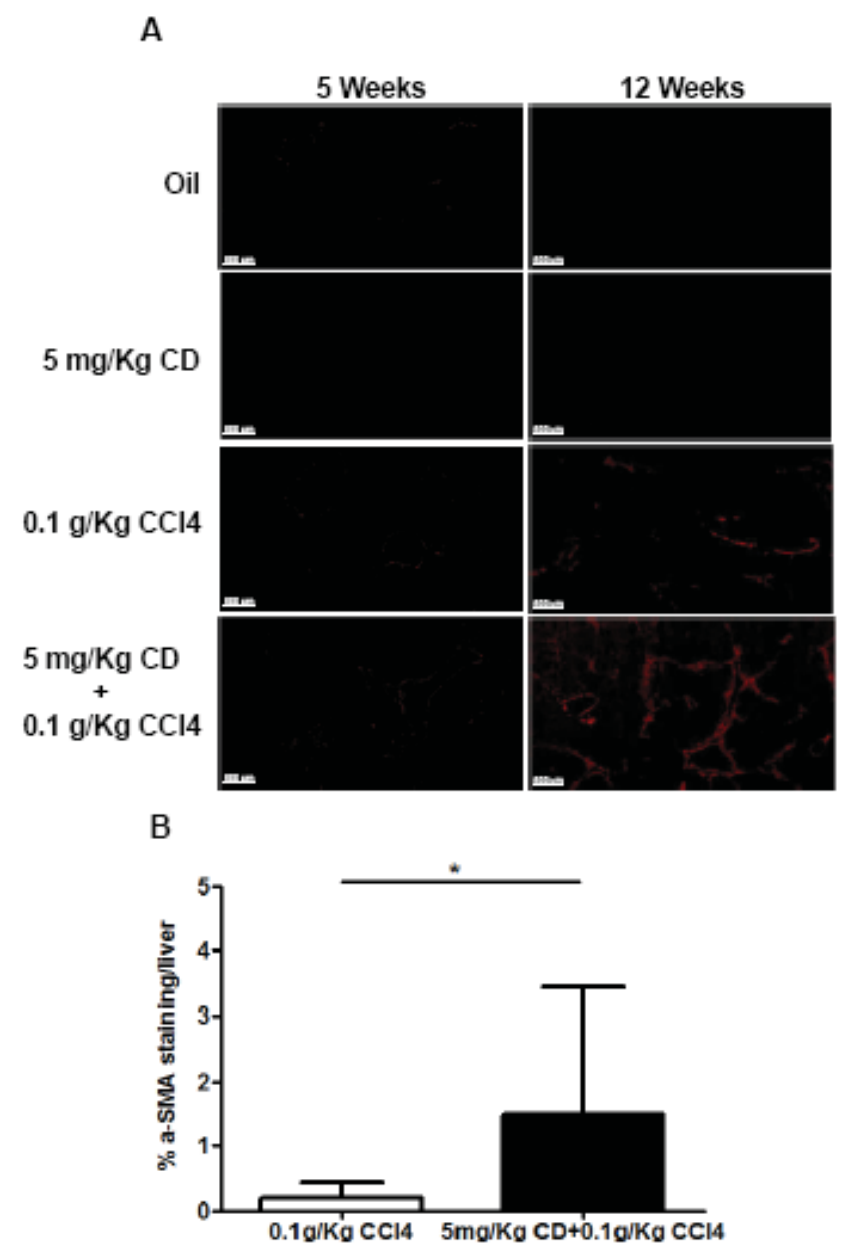

